\title{
Prevention of Electrostatic Charge Generation in Filtration of Low-Conductivity Oils by Surface Modification of Modern Filter Media
}

\author{
Johannes Staudt, John K. Duchowski \& Stephan Leyer
}

To cite this article: Johannes Staudt, John K. Duchowski \& Stephan Leyer (2020): Prevention of Electrostatic Charge Generation in Filtration of Low-Conductivity Oils by Surface Modification of Modern Filter Media, Tribology Transactions, DOI: 10.1080/10402004.2019.1690084

To link to this article: https://doi.org/10.1080/10402004.2019.1690084

Accepted author version posted online: 06 Nov 2019.

Published online: 08 Jan 2020.

\section{Submit your article to this journal $๘$}

a

View related articles $\sqsubset$

View Crossmark data $\nearrow$ 


\title{
Prevention of Electrostatic Charge Generation in Filtration of Low-Conductivity Oils by Surface Modification of Modern Filter Media
}

\author{
Johannes Staudt ${ }^{\mathrm{a}}$, John K. Duchowski ${ }^{\mathrm{b}}$, and Stephan Leyer ${ }^{\mathrm{a}}$ \\ ${ }^{a}$ Faculty of Science, Technology and Communication, Campus Kirchberg, University of Luxembourg, Kirchberg, Luxembourg; ${ }^{\text {bHYDAC }}$ \\ FluidCareCenterGmbH ${ }^{\circledR}$, Sulzbach, Germany
}

\begin{abstract}
The electrostatic charging behavior of filter elements operating in various hydraulic and lubricating fluids has been re-examined from the perspective of fundamental material properties of the two materials participating in the event. In contrast to the previously proposed mechanisms that focused predominantly on fluid and material conductivities, new evidence strongly suggests that the relative placement of the substrates in the triboelectric series must be taken into account. The positions occupied in the triboelectric series account for the donor/acceptor tendencies exhibited by the materials when brought close together in close proximity $(\leq 10 \mathrm{~nm})$. Nevertheless, this behavior is only an outward manifestation of the deeper underlying characteristics that include material surface energies and, looking even deeper, the associated electron work functions of the interacting materials. Herein we provide several examples of the enhanced understanding of the electrostatic charging/discharging (ESC/ESD) phenomena as they occur in the course of filtration of hydraulic and lubricating fluids through modern filter elements constructed of synthetic glass fiber and polymer materials.
\end{abstract}

\section{ARTICLE HISTORY}

Received 14 August 2019

Accepted 3 November 2019

\section{KEYWORDS}

Low conductive oils; filtration; electrostatic charging; surface modification; contact angle measurement; contact potential; triboelectric properties

\section{Introduction}

The occurrence of electrostatic charge (ESC) in liquids is a well-known phenomenon that has been gaining increasing attention, especially since the introduction of more highly refined base stocks and the entry of ashless formulations into the market in the late 1990s and early 2000s (Kuhnlein, et al. (1); Duchowski (2)).

Present-day hydraulic and lubrication applications place highly demanding requirements on the functional fluids employed in those systems. A majority of these fluids are hydrocarbon-based mineral oils of various degrees of refinement. The lubricating oils typically used in turbine lubrication systems are of the ISO VG 32 or ISO VG 46 type and are generally considered to be American Petroleum Institute (API) Group II or higher. In the API classification, oils are classified into Group I (solvent extracted), Group II (hydrotreated), and Group III (hydrocracked; Duchowski (2); Pavey (3)). More severe processing results in lower sulfur and unsaturated content, as well as higher viscosity indices (from 95 to 120), increasing from Group I to Group III. In general, a higher degree of refinement results in a higher quality base stock typified by better oxidative stability and a higher viscosity index, both of great benefit and therefore highly desirable for a great majority of applications. In view of these benefits, there is a general trend to gradually replace
Group I with Group II or Group III oils in nearly all industrial hydraulic and lubrication applications (Duchowski (2)).

These developments notwithstanding, a previously unforeseen and generally unexpected result of a higher degree of refinement has been the significantly lower conductivity of these base stocks. Coupled with ash-free formulations, the reduction in charge-carrying species present in the formulated products has yielded conductivities in the low double digits or, in the case of gas-to-liquid base stocks, even in the single-digit range. Moreover, the typical increase in conductivity with temperature is markedly much lower and prevents reaching conductivities sufficient for charge dissipation even under steady-state, normal operating conditions (Pavey (3)). Based on ample literature, it is generally accepted that the first necessary and sufficient condition required for the onset of ESC/electrostatic discharge (ESD) is that the oil conductivity be $\leq 500 \mathrm{pS} \mathrm{m}^{-1}$ (Kuhnlein, et al. (1); Duchowski (2); Pavey (3); Lang (4); Sasaki (5); Phair, et al. (6); Leonard and Carhart (7); Huber and Sonin (8)). Consequently, where ESC/ESD phenomena were previously mostly limited to cold start conditions $\left(\leq 20^{\circ} \mathrm{C}\right)$, they are now routinely observed and recorded even at normal operating temperatures $\left(\geq 50^{\circ} \mathrm{C}\right.$; Duchowski (2); Lang (4)).

The second condition necessary and sufficient for the onset of the ESC/ESD phenomena is the so-called hydraulic load (HL) or, effectively, the oil flux through the filter 


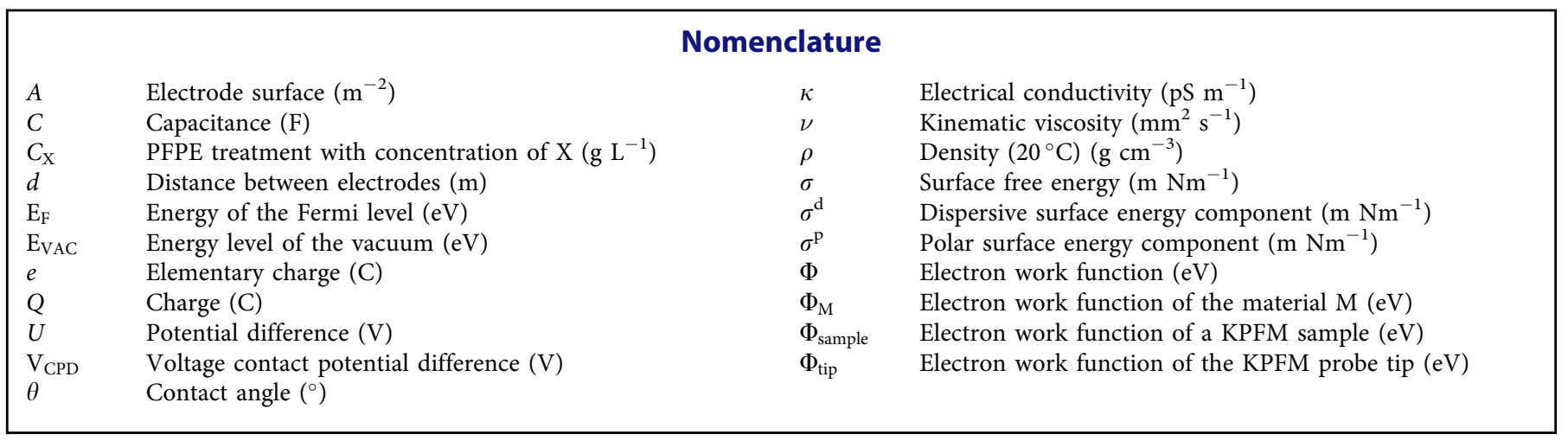

element. It is expressed in terms of liters per minute per square centimetre $\left(\mathrm{L} \min ^{-1} \mathrm{~cm}^{-2}\right)$. Nearly all laboratory and field measurements confirm that the onset of ESC/ESD occurs when the oil conductivity is less than $500 \mathrm{pS} \mathrm{m} \mathrm{m}^{-1}$ and the $\mathrm{HL}$ exceeds $0.01 \mathrm{~L} \mathrm{~min}^{-1} \mathrm{~cm}^{-2}$ (Duchowski (2)). Consequently, the most severe operating conditions most often leading to the occurrence of ESC/ESD phenomena in turbine lube applications are flushing operations performed under cold start conditions.

In general, numerous modern hydraulic and lubricating systems tend to exhibit higher tendencies toward the ESC/ESD phenomena as a result of higher flow velocities, advanced filter element design based on synthetic materials, finer filter porosities with higher filtration efficiencies, and the use of highly refined, ashless oil formulations (Pavey (3); Sasaki (5); Phair, et al. (6); Leonard and Carhart (7); Huber and Sonin (8)).

In this article, we present new evidence to enhance the understanding of the root causes underlying the onset of ESC/ESD phenomena in hydraulic and lubricating systems. The overall result can be expressed in terms of the actual physical principles driving these processes at the filter-fluid interface. In turn, this new insight led us to the development of novel specialty materials that prevent the occurrence of ESC/ESD in a wide variety of fluids under a proven range of operating conditions. The enhanced model developed within the framework of the current investigation, as well as the results of ESC/ESD prevention with newly prepared filter materials, is presented herein.

\section{Theoretical basics}

\section{Model of electrostatic charging in solids}

Contact charging occurs as a result of interaction between solid substrates or their interaction with the surrounding media, liquid or gas, as shown in Fig. 1. Here, it is important to distinguish between the conductors and insulators. For example, if two metals are rubbed together, the charge transfer will not be greater than that resulting from ordinary contact between them. "Ordinary" here means simple touching, with no rubbing or friction involved (Kuhnlein, et al. (1); Lang (4); Lüttgens (9)). Insulators exhibit a fundamentally different behavior (Scheffler (10); Lowell and RoseInnes (11)). Specifically, friction creates a much larger surface charge than that arising from a simple contact
(Scheffler (10)). The charge generation between solids can be explained in terms of their respective electron work functions. In the physical model, the work function is defined as the work required to remove an electron from the surface and transport it to infinity as follows:

$$
\Phi=E_{\mathrm{VAC}}-E_{\mathrm{F}}
$$

Charge separation has been described by several models. Charge separation results from the contact of molecules with different work functions $\Phi$, with no friction required. However, the two materials must be brought together in close proximity (Kuhnlein, et al. (1); Phair, et al. (6); Scheffler (10)). Friction only serves to increase the surface contact area. This is illustrated in Figs. 1a-1d. In these figures, the two materials are brought together in close proximity $(\leq 10 \mathrm{~nm})$. Within this close proximity, charge transfer occurs at the interface as a result of the electrons moving from the material with the lower work function to that with the higher work function (Kuhnlein, et al. (1)). This leads to the formation of a double layer at the interface, referred to as the Helmholtz double layer (Kuhnlein, et al. (1); Lang (4); Helmholtz (12)). The double layer creates a voltage potential difference referred to as the voltage contact potential difference or $V_{\mathrm{CPD}}$ :

$$
V_{\mathrm{CPD}}=\frac{\left(\Phi_{\mathrm{M} 1}-\Phi_{\mathrm{M} 2}\right)}{e},
$$

where $\Phi_{\mathrm{M} 1}$ and $\Phi_{\mathrm{M} 2}$ are the work functions of the two materials and $e$ is the elementary charge. Initially, at close proximity, the magnitude of $V_{\mathrm{CPD}}$ is in the millivolt range. $V_{\mathrm{CPD}}$ forms a barrier to electron transfer between the two materials, thereby preventing charge recombination. On the other hand, a thermodynamic equilibrium negating the potential difference is achieved when $V_{\mathrm{CPD}}+\Phi_{\mathrm{M} 2}=\Phi_{\mathrm{M} 1}$ is achieved (Scheffler (10)). When the separation occurs on a very short timescale, charge recombination cannot take place and the high-voltage amplitudes are reached even faster (Kuhnlein, et al. (1)). Upon material separation, $V_{\mathrm{CPD}}$ increases in a manner exactly analogous to that of a plate capacitor and can reach values as high as tens of kilovolts (Lang (4)):

$$
Q=\mathrm{C} \cdot \mathrm{U}
$$

with the charge $Q$, capacitance $C$, and potential difference $U$ (where $U=V_{\mathrm{CPD}}$ ). The capacitance can then be expressed as follows: 


$$
C=\varepsilon_{0} \cdot \varepsilon_{r} \cdot \frac{A}{d}
$$

and

$$
U=\frac{Q}{C},
$$

where $A$ is the electrode surface, $d$ is the distance between the electrodes, and $\varepsilon_{0}$ and $\varepsilon_{0}$ are the permittivity of free space and the relative permittivity of the two materials, respectively.

\section{Correlation between the surface energy and the work function}

In order to determine the charging tendencies of the two materials in close proximity or in direct contact with each other, it is necessary to determine their respective work functions. However, in this regard, Choi, et al. (13) showed that by attempting to alter the material work function, they effected changes in the polymer wetting behavior. They also a)

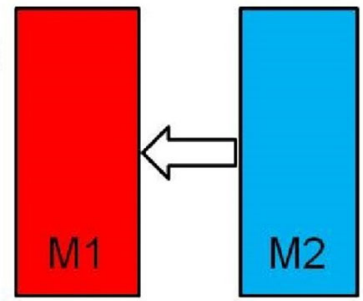

Contact

c)

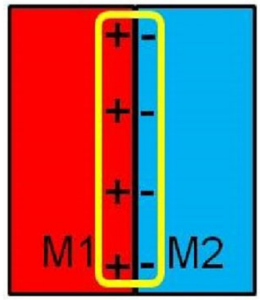

Partial charge balancing b)

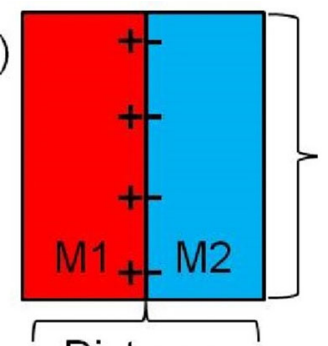

Distance $d \leq 10 \mathrm{~nm}$

d)
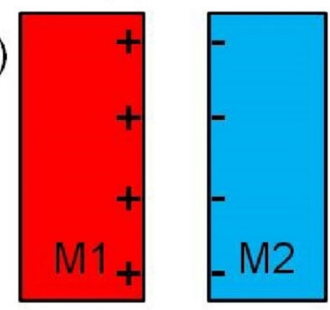

Electrostatic charged bodies
Figure 1. Schematic description of the charge separation process for solid bodies, based on Kuhnlein, et al. (1) and Scheffler (10). showed that a good correlation exists between the work function and the wetting behavior for the polymers they investigated (Choi, et al. (13)). Subsequently, from the observed wetting behaviour, the respective surface energies of various substrates can be derived, which in turn provides a correlation between surface energies and the respective electron work functions measured independently by Kelvin probe force microscopy (KPFM).

In the present work, our aim was to determine the work functions for several standard reference materials from direct measurements with KPFM and to correlate them with their respective surface energies determined from contact angle measurements. The obtained correlation would be placed within the framework of the triboelectric series initially presented by Johan Wilcke (1757), as shown in Fig. 2 (top; Wang, et al. (14); Lee (15)). The original series was published in order to explain the relative charging tendencies of various material pairs to account for the ESC between them. Our intent was to establish a correlation to predict ESC tendencies of the materials used in typical industrial filtration applications in relation to the functional fluids employed therein.

The intent was to provide an advance estimate of the charging potential of material pairings in the filtration of lowconductivity oils in order to select or modify filter materials for the respective application to reduce or entirely eliminate ESC.

\section{Experimental}

\section{Determination of wetting characteristics}

The wetting characteristics of the select raw and treated substrates were determined from contact angle measurements carried out on a contact angle measurement instrument. Deionized water and diiodomethane $\left(\mathrm{CH}_{2} \mathrm{I}_{2}\right)$ were used as the test fluids. When possible the sessile drop method (Quéré (16); Staudt, et al. (17)) was employed for this purpose. Alternatively, for substrates that did not allow for proper droplet formation, the captive bubble procedure was employed (Quéré (16); Staudt, et al. (17); KRÜSS GmbH (18); Cherif (19); Slepickova Kasalkova, et al. (20)). The corresponding contact angle measurement procedures for each method are depicted in Fig. 3.

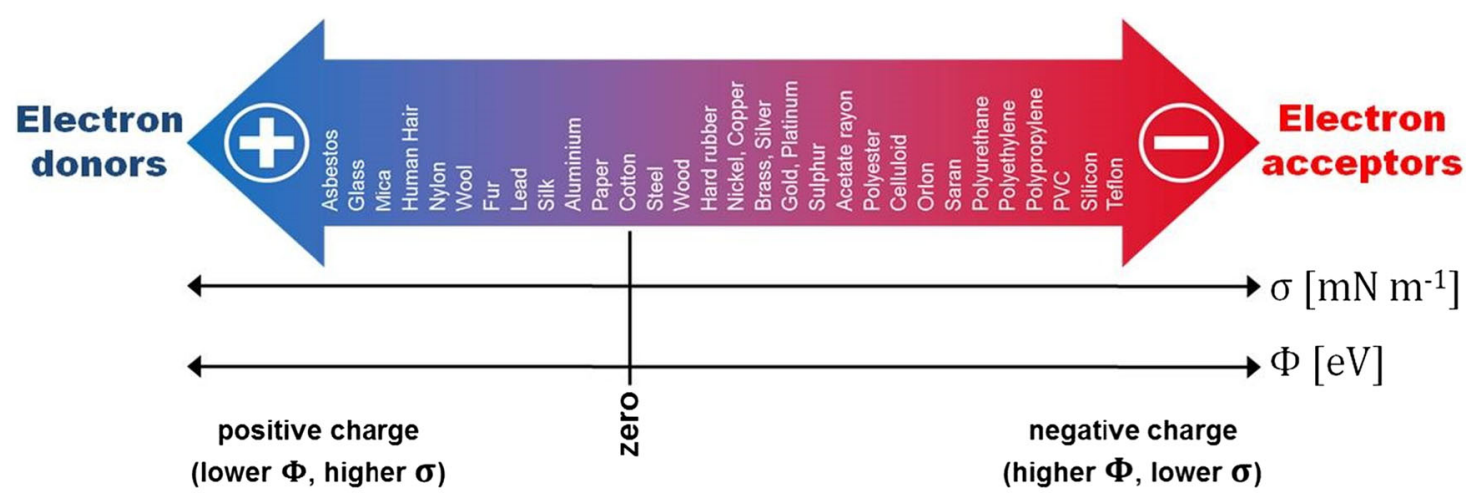

Figure 2. (Top) Materials order within the triboelectric series accounting for their relative charging tendencies (Wang, et al. (14)). (Bottom) Relationship between surface energies and work functions of various substrates within the context of the triboelectric series (EDS-Systems (45)). 


\section{Determination of electron work functions}

The respective contact potentials and thus the electron work functions $\Phi_{M}$ of select raw and treated substrates were determined on an amplitude-modulated (AM) KPFM, where the contact potential difference $V_{\mathrm{CPD}}$ was determined (Volta and Banks (21); Vilitis, et al. (22, 23)). In addition, the electrical potential distributions of sample surfaces were mapped as described in the literature (Rezende, et al. (24); Nonnenmacher, et al. (25); Jacobs, et al. (26); Kikukawa, et al. (27); Weaver (28); Sadewasser and Glatzel (29)). The working principle of the KPFM is illustrated in the diagram in Fig. 4.

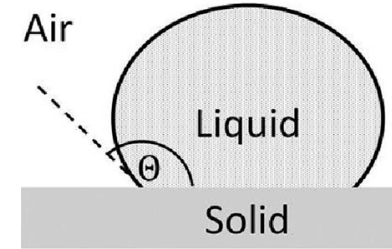

a)

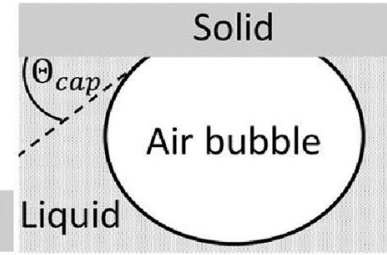

b)
Figure 3. (a) Sessile drop method (Staudt, et al. (17); Cherif (19)) and (b) captive bubble method (KRÜSS GmbH (18)).

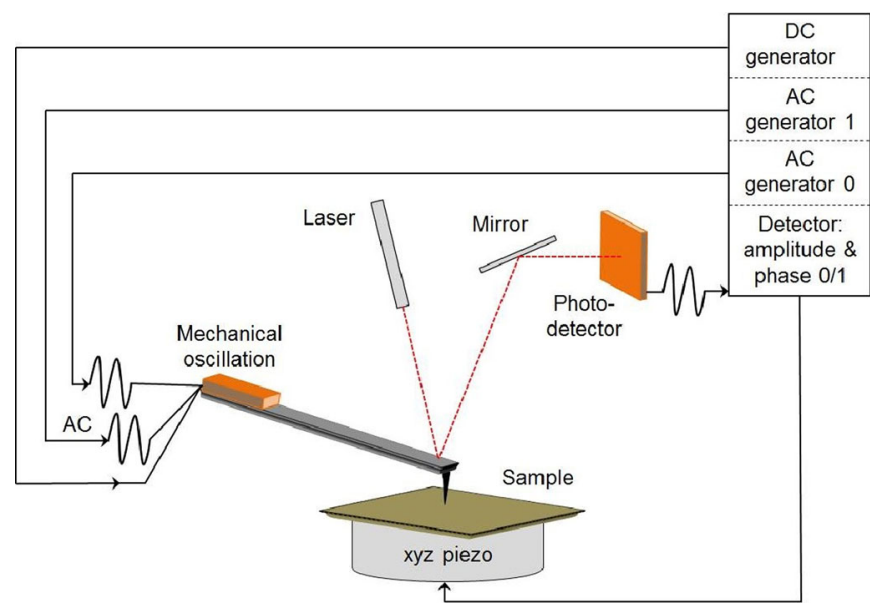

Figure 4. Schematic setup of the KPFM (Galembeck, et al. (46); Galembeck, et al. (47)).
The KPFM directly measures the $V_{\mathrm{CPD}}$ between the probe tip and the chosen substrate. The respective electron work function $\Phi_{M}$ of the latter is then calculated as the probe tip is referenced to a standard material, the highly oriented pyrolytic graphite with the known work function value of $4.6 \mathrm{eV}$ (Rezende, et al. (24); Nonnenmacher, et al. (25)).

$$
V_{\mathrm{CPD}}=\frac{\left(\Phi_{\text {tip }}-\Phi_{\text {sample }}\right)}{\mathrm{e}} \Phi_{\text {sample }}=\Phi_{\text {tip }}-e \cdot V_{\mathrm{CPD}}
$$

For example, the electron work function of one substrate has been determined as follows:

$$
\Phi_{\mathrm{PCTFE}}=\Phi_{\mathrm{tip}}-e \cdot V_{\mathrm{CPD}}=4.6 \mathrm{eV}-0.25 \mathrm{eV}=4.35 \mathrm{eV} .
$$

\section{Evaluation of the electrostatic charging behavior}

The ESC tendencies of the raw and surface-treated substrates were evaluated on a special test stand built in-house for this purpose. In order to alter the surface properties of the standard glass fiber filter media substrate, we employed a generic perfluoropolyether (PFPE)-based coating agent. We selected one of many generic compounds representative of this class of surface-active materials. One example is (but is not limited to) Sigma Aldrich Fomblin ${ }^{\circledR}$ Y (CAS Reg. No. 69991-67-9, with a general chemical structure of $\mathrm{CF}_{3} \mathrm{O}\left[-\mathrm{CF}\left(\mathrm{CF}_{3}\right) \mathrm{CF}_{2} \mathrm{O}\right.$ ]$\left._{x}\left(-\mathrm{CF}_{2} \mathrm{O}-\right)_{\mathrm{y}} \mathrm{CF}_{3}\right)$. In order to ensure the validity of measurements, the test stand was certified by SGS TÜV and DEKRA representatives (Technischer Überwachungsverein [TÜV], Société Générale de Surveillance [SGS] (30); DEKRA Exam

Table 1. Relationship between temperature, electrical conductivity, and viscosity of the turbine oil employed in our investigations.

\begin{tabular}{lcc}
\hline & $\begin{array}{c}\text { Electric } \\
\text { Temperature }\left({ }^{\circ} \mathrm{C}\right)\end{array}$ & $\begin{array}{c}\text { Kinematic } \\
\left.\text { conductivity } \kappa(\mathrm{ps} \mathrm{m})^{-1}\right)\end{array}$ \\
\hline 20 & 5.6 & 120.25 \\
25 & 7.1 & 90.80 \\
30 & 10.1 & 69.95 \\
35 & 13.4 & 54.87 \\
40 & 17.5 & 43.76 \\
45 & 22.7 & 35.43 \\
50 & 28.8 & 29.07 \\
\hline
\end{tabular}

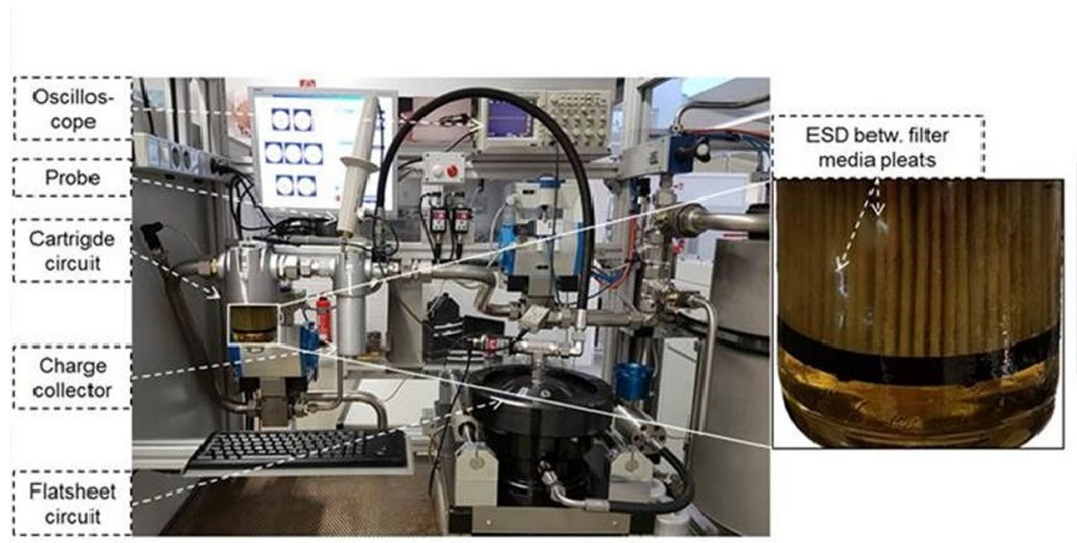

a)

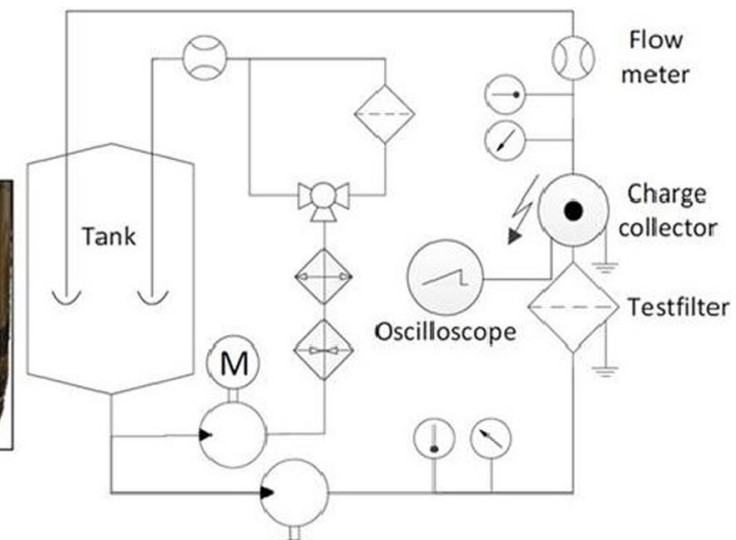

(M)

b)

Figure 5. (a) In-house-built ESC test stand to determine electrostatic charging during the filtering process and (b) hydraulic circuit diagram of the ESC test stand. 
Table 2. Properties of functional fluid.

\begin{tabular}{|c|c|c|c|c|c|c|}
\hline Functional fluid & $\begin{array}{l}\theta \text { on pure } \\
\operatorname{PFPE}\left({ }^{\circ}\right)\end{array}$ & $\begin{array}{l}\text { Surface energy } \\
\sigma\left(\mathrm{m} \mathrm{Nm}^{-1}\right)\end{array}$ & $\begin{array}{l}\text { Dispersive surface } \\
\text { energy component } \\
\sigma^{d}\left(\mathrm{~m} \mathrm{Nm}^{-1}\right)\end{array}$ & $\begin{array}{l}\text { Polar surface energy } \\
\text { component } \sigma^{\mathrm{p}}\left(\mathrm{m} \mathrm{Nm}^{-1}\right)\end{array}$ & $\begin{array}{c}\text { Density } \\
\rho\left(20^{\circ} \mathrm{C}\right)\left(\mathrm{g} \mathrm{cm}^{-3}\right)\end{array}$ & $\begin{array}{c}\text { Kinematic viscosity } \\
\nu\left(40^{\circ} \mathrm{C} \mid 100^{\circ} \mathrm{C}\right) \\
\left(\mathrm{mm}^{2} \mathrm{~s}^{-1}\right)\end{array}$ \\
\hline Turbine oil & 81.78 & 30.78 & 30.02 & 0.76 & 0.801 & $43.76 \mid 6.90$ \\
\hline
\end{tabular}

Table 3. High-purity base materials for the determination of surface energy and work function.

\begin{tabular}{lllr}
\hline Sample & \multicolumn{1}{c}{ Material } & Form & \multicolumn{1}{c}{ CAS-No. } \\
\hline Glass reference & Borosilicate & Plate & $65997-17-3$ \\
PTFE & Polytetrafluoroethylene & Plate & $9002-84-0$ \\
PVDF & Poly(vinylidene fluoride) & Plate & $24937-79-9$ \\
PA6 & Polyamide 6 & Plate & $25038-54-4$ \\
HDPE & Polyethylene & Plate & $9002-88-4$ \\
PP & Polypropylene & Plate & $9003-07-0$ \\
PDMS & Polydimethylsiloxane & Plate & $9016-00-6$ \\
PCTFE & Polychlorotrifluoroethylene & Plate & $9002-83-9$ \\
\hline
\end{tabular}

Table 4. Measured surface free energy and their components and corresponding work function values compared to highly oriented pyrolytic graphite. ${ }^{\text {a }}$

\begin{tabular}{|c|c|c|c|c|}
\hline Sample & $\sigma\left(\mathrm{mN} \mathrm{m}^{-1}\right)$ & $\sigma^{\mathrm{d}}\left(\mathrm{mN} \mathrm{m}^{-1}\right)$ & $\sigma^{\mathrm{p}}\left(\mathrm{mN} \mathrm{m}^{-1}\right)$ & $\Phi_{\text {sample }}(\mathrm{eV})$ \\
\hline Glass reference & 58.71 & 40.21 & 18.50 & 3.63 \\
\hline PA6 & 42.40 & 36.96 & 5.44 & 3.89 \\
\hline PP & 31.50 & 31.50 & 0.00 & 4.26 \\
\hline PVDF & 30.85 & 28.28 & 2.57 & 4.30 \\
\hline HDPE & 31.72 & 29.61 & 1.11 & 4.35 \\
\hline PCTFE & 28.60 & 30.08 & 6.69 & 4.35 \\
\hline PDMS & 19.67 & 19.63 & 0.04 & 4.73 \\
\hline PTFE & 19.37 & 18.83 & 0.54 & 5.57 \\
\hline GF filter media & 57.70 & 34.1 & 23.41 & $\mathrm{~b}$ \\
\hline Surface agent ${ }^{c}$ & 7.61 & 7.26 & 0.34 & 5.30 \\
\hline
\end{tabular}

asee Table 3 for definitions.

${ }^{\mathrm{b}}$ Not directly measurable with KPFM.

'Modified PFPE dried on a typical microscopy borosilicate glass plate (glass reference)

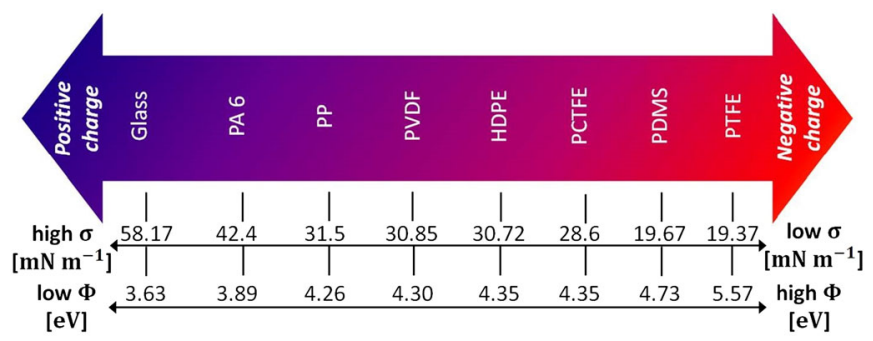

Figure 6. Classification of the basic materials in the triboelectric series (Lee (15)).

(31)). The tests were carried out with an electric field meter that measures the magnitude of the potential at a predefined fixed distance from a Plexiglas filter housing permeable to electromagnetic radiation.

The corresponding charging behavior for each filter material was determined at flow rates from 0 to $10 \mathrm{~L} \mathrm{~min}$ m $^{-1}$ in continuous ramp-up mode with temperatures ranging from 20 to $50^{\circ} \mathrm{C}$ in $5^{\circ} \mathrm{C}$ steps. A picture of the test stand is shown in Fig. 5a and a hydraulic circuit diagram is shown in Fig. 5 b.

The test stand operates with a standard turbine lubricating oil (ChevronTexaco Regal Premium EP) of the ISO VG 46 grade. The oil contains a thiophosphate-based extremepressure additive in addition to the standard rust and oxidation prevention additive package. The electrical conductivity of the working fluid was determined with a conductivity sensor in accordance with ASTM D2624 (32). In addition, the oil kinematic viscosity was determined with a viscometer in accordance with ASTM D7042 (33). The corresponding oil properties of the fluid employed in the test stand are provided in Tables 1 and 2 .

\section{Results}

The wetting characteristics and electron work functions of several standard materials (Table 3 ) were determined first to establish their proper arrangement within the triboelectric series. The results of these measurements are listed in Table 4 and depicted pictorially in Fig. 6.

The corresponding wetting properties of the investigated glass fiber (GF) filter material and of the surface treatment agent (prepared, deposited, and dried on a reference glass slide) were determined from the contact angle measurements depicted in Fig. 7 and are summarized in Table 5.

The data presented in Table 6 also illustrate the changes in the substrate wetting behavior and the working fluid in response to increasing dosage of surface treatment.

\section{Evaluation of the electrostatic charging behavior}

An example of an ESC measurement result carried out at $50{ }^{\circ} \mathrm{C}$ with the flow rate ranging from 0 to $10 \mathrm{~L} \mathrm{~min}^{-1}$ (with the corresponding $\mathrm{HL}$ of 0 to $0.157 \mathrm{~L} \mathrm{~min} \mathrm{~mm}^{-1}$ ) is displayed in the diagram in Fig. 8.

The changes in the ESC behavior of the filter material substrate in response to an increasing concentration (Table 6) of the surface treatment are depicted in Figs. 9a-9d corresponding to raw material and surface treatment doses of 1,10 , and $100 \mathrm{~g} \mathrm{~L}^{-1}$, respectively.

\section{Discussion}

The experimental results of wetting characteristics expressed in terms of the respective contact wetting angles and the corresponding surface energies for various substrates reported in the previous section are in good agreement with values reported in the literature (Morra, et al. (34); Owens and Wendt (35); Good (36); Suzuki, et al. (37); Wu (38)). The same can be said of the experimentally obtained electron work functions (Jachowicz, et al. (39)). Even a cursory glance at the data reported Table 4 shows that a correlation exists between the surface energies and the electron work functions for various substrates investigated herein, as shown in Fig. 10.

The main intent was to arrange the investigated substances to place them in proper order within the triboelectric series. Because the oil properties, particularly the electron 


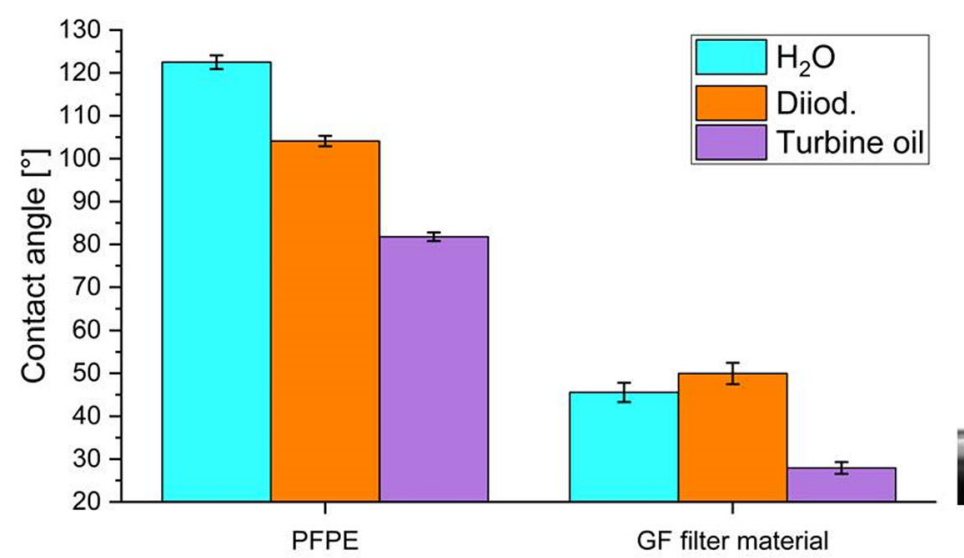

a)

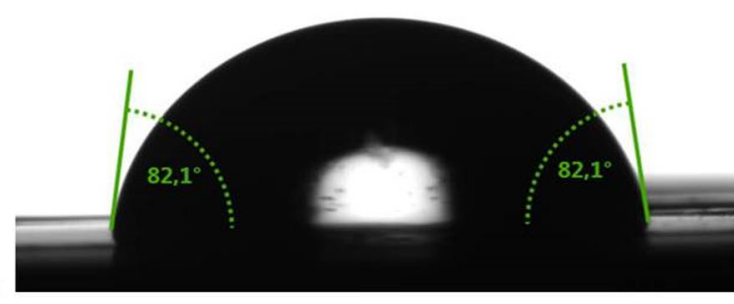

b)

Figure 7. (a) Measured contact angles $\theta$ on GF filter material and on pure dried surface agent (and (b) contact angle $\theta$ of turbine oil on pure surface-active agent.

Table 5. Determined surface energy of the dried surface-active agent and the GF filter material.

\begin{tabular}{|c|c|c|c|c|c|}
\hline Substrate & $\theta$ Deionized $\mathrm{H}_{2} \mathrm{O}\left({ }^{\circ}\right)$ & $\theta$ Diiodomethane $\left({ }^{\circ}\right)$ & $\begin{array}{c}\text { Surface free } \\
\text { energy } \sigma\left(\mathrm{mN} \mathrm{m}^{-1}\right)\end{array}$ & $\begin{array}{c}\text { Dispersive surface } \\
\text { energy component } \\
\sigma^{d}\left(\mathrm{mN} \mathrm{m}^{-1}\right)\end{array}$ & $\begin{array}{c}\text { Polar surface energy } \\
\text { component } \\
\sigma^{\mathrm{p}}\left(\mathrm{mN} \mathrm{m}^{-1}\right) \\
\end{array}$ \\
\hline GF filter media & 45.6 & 50.0 & 57.70 & 34.29 & 23.41 \\
\hline PFPE $^{a}$ & 122.6 & 104.1 & 7.61 & 7.26 & 0.34 \\
\hline
\end{tabular}

${ }^{a}$ Modified PFPE dried on a typical microscopy borosilicate glass plate (glass reference).

Table 6. Determined contact angles $\theta$ on treated substrates with different concentrations of surface active agent.

\begin{tabular}{lccc}
\hline Concentration of PFPE $\left(\mathrm{g} \mathrm{L}^{-1}\right)$ & $\theta \mathrm{DI}-\mathrm{H}_{2} \mathrm{O}\left({ }^{\circ}\right)$ & $\theta$ Diiodomethane $\left(^{\circ}\right)$ & $\theta$ Turbine oil $\left(^{\circ}\right)$ \\
\hline 0 & $45.6^{\mathrm{a}}$ & $50.0^{\mathrm{a}}$ & $27.9^{\mathrm{a}}$ \\
1 & 129.6 & 112.1 & $25.4^{\mathrm{a}}$ \\
10 & 149.9 & 133.7 & 144.1 \\
100 & 161.6 & 141.8 & 150.2 \\
300 & 164.6 & 145.1 & 153.0 \\
\hline
\end{tabular}

${ }^{\mathrm{a}}$ In contrast to the other values measured with the captive bubble method (KRÜSS GmbH (18)).

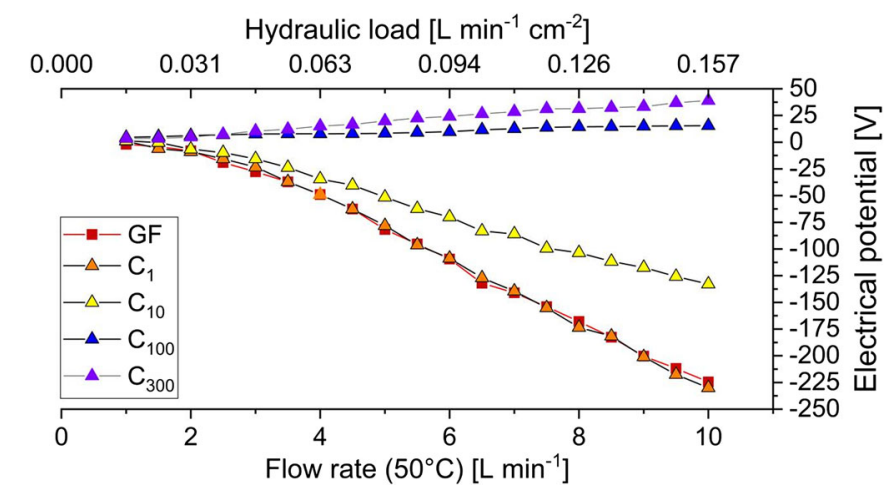

Figure 8. Example of an ESC measurement result carried out at $50^{\circ} \mathrm{C}$ with the flow rate of 0 to $10 \mathrm{~L} \mathrm{~min}^{-1}$ for different materials.

work function, could not be obtained directly, we selected a number of suitable polymeric reference materials to approximate the oil characteristics in the solid form. These polymers (polyethylene [HDPE], polypropylene [PP]) are purely hydrocarbon based and can be thought of as oils in solid form. The choice of other materials was based on the need to fill the remaining data points to cover the entire range of the triboelectric series of interest for our investigations.

The obtained data lent itself to a fit by a second-order polynomial (Eq. [8]) that may or may not represent the actual physical behavior. However, we found it sufficiently suitable to establish a relationship between the surface energy and the work function for the range of interest in case of the investigated substances.

$$
y(x)=16.455 \mathrm{x}^{2}-171.3 x+462.57
$$

with a correlation coefficient of $R^{2}=0.9873$ demonstrating the goodness of fit.

Because it was not possible to directly determine the work function for all of the investigated substances due to surface irregularities (GF filter media) or dielectric properties (lubricating oil), we used the correlation between the directly measured property (surface energy) to obtain the value of interest (work function). This step was required because our goal was to express the electrostatic charging tendencies in terms of the fundamental physical quantities ( $V_{\mathrm{CPD}}$ and the respective $\Phi_{\mathrm{M} 1}$ and $\Phi_{\mathrm{M} 2}$ ). The intent was to establish a framework based on the fundamental physical quantities for optimal description of the ESC behavior that occurs at the oil-filter media interface; that is, when $V_{\mathrm{CPD}}=0$ no charging should occur.

The correlation obtained from the fit appears to be relatively good in that for the GF filter media $\left(\sigma_{\mathrm{GF}}=57.70 \mathrm{mN} \mathrm{m}^{-1}\right)$ we obtained $\Phi_{\mathrm{GF}}=3.63 \mathrm{eV}$, which is in excellent agreement with that measured directly for the 

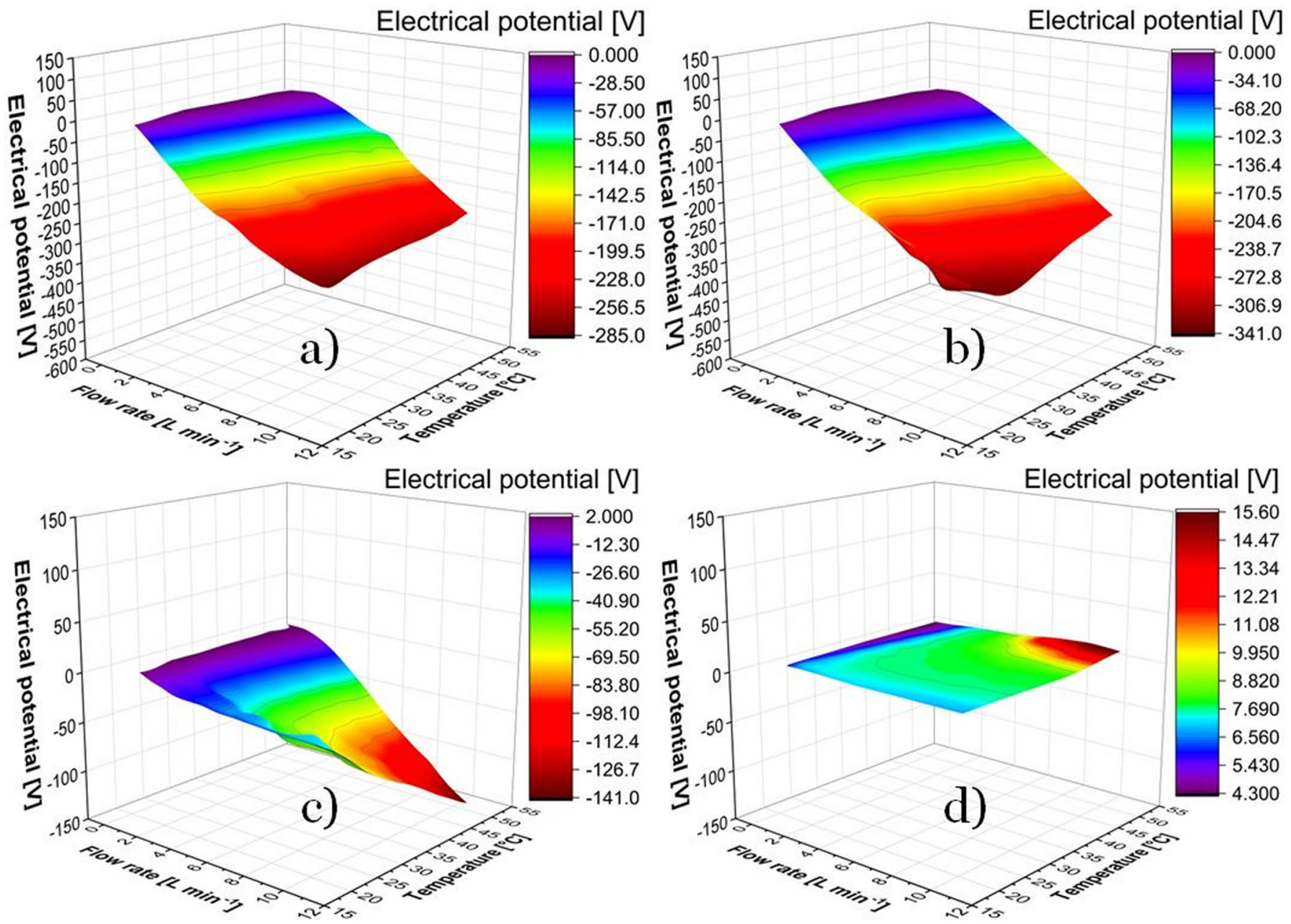

Figure 9. (a) Standard GF filter media and (b) PFPE surface treatment with concentrations of $1 \mathrm{~g} \mathrm{~L}^{-1}$, (c) $10 \mathrm{~g} \mathrm{~L}^{-1}$, and (d) $100 \mathrm{~g} \mathrm{~L}^{-1}$, respectively.

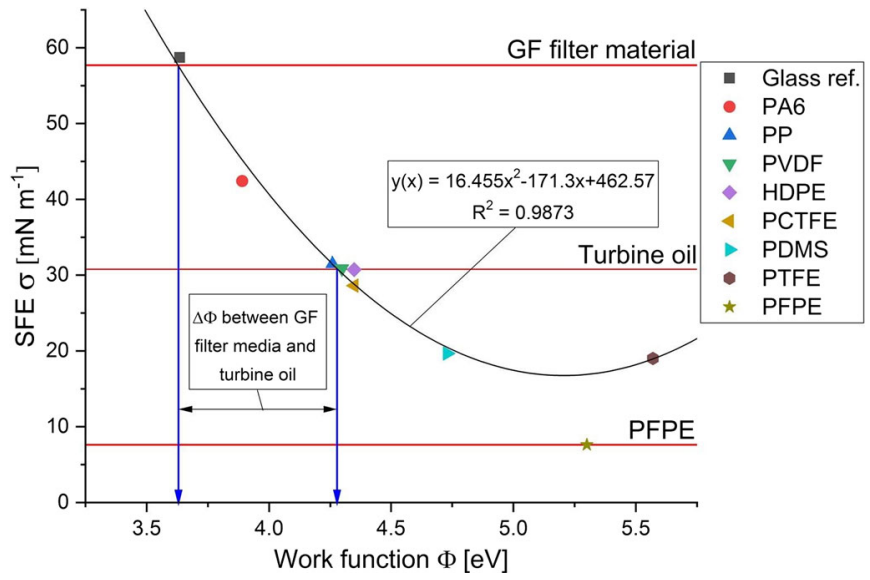

Figure 10. Display of the determined values for surface free energy $\sigma$ and work function $\Phi$ including the surface energy for the GF filter material and the turbine oil.

borosilicate glass reference slide $\left(\sigma_{\mathrm{Glass} r e f}=58.71 \mathrm{mN} \mathrm{m}^{-1}\right.$ and $\Phi_{\text {Glass ref. }}=3.64 \mathrm{eV}$ ). Similarly, for the lubricating oil $\left(\sigma_{\mathrm{oil}}=30.78 \mathrm{mN} \mathrm{m}^{-1}\right)$, the fit yielded a value of $\Phi_{\mathrm{oil}}=$ $4.27 \mathrm{eV}$, which compares very well to the values measured directly for the HDPE $\left(\sigma_{\mathrm{HDPE}}=31.72 \mathrm{mN} \mathrm{m}^{-1}\right.$ and $\left.\Phi_{\mathrm{HDPE}}=4.35 \mathrm{eV}\right) \quad$ and $\quad \mathrm{PP} \quad\left(\sigma_{\mathrm{PP}}=31.50 \mathrm{mN} \mathrm{m}^{-1}\right.$ and $\left.\Phi_{\mathrm{PP}}=4.26 \mathrm{eV}\right)$.

\section{Electrostatic charging behavior}

Having filled the triboelectric series with the respective surface energies and work functions of the investigated substrates, our model describing the corresponding electrostatic charging tendencies among them was complete. In general, it provides a framework similar to that provided by the electronegativity values for chemical elements in the periodic table. The larger the potential difference, the greater the propensity for charge transfer to occur. Consequently, the greater the $V_{\mathrm{CPD}}$ between the two substances, the greater the tendency for ESC to occur between them. For example for the glass-HDPE pair, $V_{\mathrm{CPD}}=0.72 \mathrm{eV}$. Therefore, a strong propensity for charge transfer to occur would be expected.

Due to its lower work function, glass becomes the donor and the HDPE an acceptor within this material pair. The same could be said of the glass-PP pair with $V_{\mathrm{CPD}}=$ $0.63 \mathrm{eV}$. Turning to the case of interest (GF filter media and the turbine lubricating oil), the respective work function values of 3.64 and $4.27 \mathrm{eV}$ yield $V_{\mathrm{CPD}}=0.63 \mathrm{eV}$; that is, equal to that between the reference borosilicate glass and PP. Based on our model, it would be expected that the GF filter material should charge positive, whereas the turbine lubricating oil should charge negative. This is indeed consistent with their respective placement within the triboelectric series as well as the observed experimental evidence. 


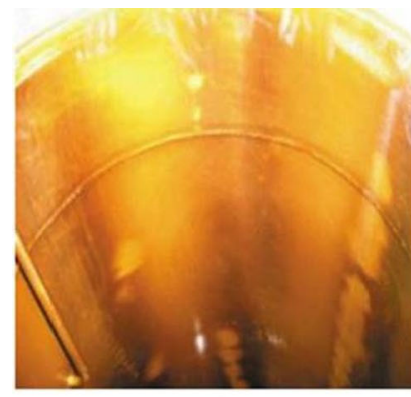

a)

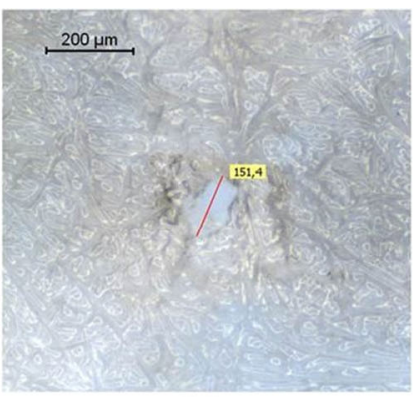

b)

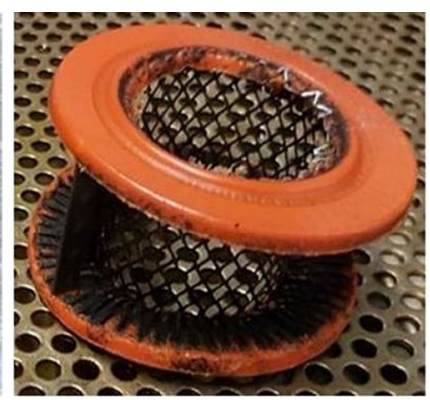

c)

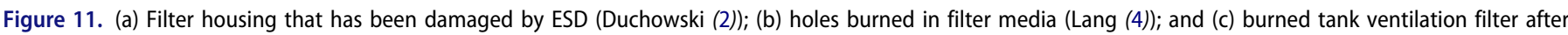
oil tank explosion due to ESD.

This behavior is well illustrated in Figs. 8 and 9, respectively, where the curve for the untreated GF filter media in Fig. 8 and the surface for the same shown in Fig. 9a exhibit the most dramatic charging behavior. In addition, a more careful examination of Fig. 9a reveals the two further dependencies of the charging behavior. These are the dependence on temperature and hence the oil conductivity (cf. Table 1) as well as the oil flow rate or the hydraulic load. The dependence on the oil conductivity has been empirically and phenomenologically observed in numerous laboratory and field investigations carried out in the course of the past 15 years by ourselves and others (Leonard and Carhart (7)). It can be explained by the reduced propensity for charge recombination to occur at the double-layer interface due to the greater oil insulating character at lower conductivities. In turn, a higher potential difference at the filter-oil interface is driven by the shorter charge separation time at increased flow rates.

The influence of the surface treatment on the charging behavior is illustrated in a stepwise fashion by curves $C_{1}$ through $\mathrm{C}_{300}$ in Fig. 8 and shown by the "surface tilt" displayed in Figs. 9b-9d. Although the exact values for surface energy or the work function could not be measured for the treated substrates (for reasons previously explained), the observed charging behavior can be accounted for by the changing nature of the GF filter media surface in response to the increasing treatment dosage (see Fig. 8, curves $C_{1}$ through $\mathrm{C}_{300}$ ). For example, when the appropriate surface character was reached, the ESC at the filter-oil interface was reduced to nil. The tunability of this approach is aptly illustrated by examining Fig. 8 (curve $\mathrm{C}_{300}$ ), which shows that at a certain point a reverse in polarity can be achieved. Taken collectively, the acquired ESC experimental data fully validate the work function/surface energy model based on the triboelectric series as an explanation for the onset and occurrence of ESC in hydraulic and lubricating systems where GF-based filter material elements are installed.

\section{Conclusion}

Numerous incidences of the occurrence of ESC/ESD phenomena in hydraulic and lubricating systems have been reported over the course of the past several years. The evidence keeps mounting that their number will increase due to the increased usage of low-conductivity oils and more demanding system operating conditions. Some of the incidents already reported include highly detrimental effects such as damage to the system components, including electronic sensors and transducers; embrittlement; and holes being burned into the filter media layers, where even arcing and deflagrations have been observed in the system reservoirs. Several examples of ESD-induced damage are shown on the photographs in Figs. 11a-11c. In addition, ESD has been clearly linked to varnish formation by initiating the free radical-driven polymerization processes of both the additives and base stocks (Duchowski (2)).

Despite all of these occurrences, no clear-cut solution to this issue has been proposed due to the lack of understanding of the fundamental physical principles governing the process. Instead, attempts were made to resolve the issue through roughshod and haphazardly applied half measures aimed at alleviating the symptoms instead of addressing the root cause. The applied "solutions" often included but were not limited to the use of conductive (wire mesh) filter elements, antistatic additives (Ahmed and Aurrecoechea (40)), or tying the filter elements with a wire.

The solution proposed herein is based on the fundamental physical principles derived from the reported experimental data. Consequently, it is aimed directly at the root cause of the phenomena, thereby eliminating its root cause. Instead of attempting to channel the already existing static charge by means of conductive elements or dissipating it through the use of additives, we have shown how to arrest charge transfer leading to the formation of the Helmholtz double layer (Lang (4); Scheffler (10); Kron (41)) in the first place. Moreover, our proposed solution has been aptly verified through copious experimental laboratory and field trial data. In addition, we have demonstrated it to be finely tunable (Schmitz, et al. (42); Duchowski and Lang $(43,44)$ ) and therefore adaptable to different oil formulations as well as to system operating conditions of varying severity, such as cold starts and flushing operations.

It is only for reasons of brevity that we cannot report the results of all of our findings; however, these may form the subject of a separate, follow-up paper. Suffice it to say that the solution proposed herein has already been adopted by several major turbine original equipment manufacturers. It is already being employed in a broad number of vastly different applications that range from turbine lubrication to 
excavator hydraulic systems to snowcat units operating in extremely harsh environments.

\section{Acknowledgements}

The authors thank the HYDAC FluidCareCenter ${ }^{\circledR} \mathrm{GmbH}$, Dr. Timo Lang, Edwin Koch, Daniel Mueller, Christian Adam, Andrei Wenzel, and Martin Noll for their help with material preparation, assistance in experimental work, and many fruitful discussions.

\section{References}

(1) Kuhnlein, M., Wendel, T., and Murrenhoff, H. (2013), "Electrostatic Charge Measurement in Hydraulic Circuits," Proceedings from the 13th Scandinavian International Conference on Fluid Power, Linköping, Sweden, June 3-5, pp 273-283. Linköping University Electronic Press. doi:10.3384/ ecp1392a27

(2) Duchowski, J. K. (2014), "Electron Spin Resonance (ESR) Spectra of Butylated Hydroxytoluene (BHT) as Evidence of Free Radical Formation in Electrostatic Discharge (ESD) Damaged Lubricating Oils," Tribologia, 256(4), pp 43-52.

(3) Pavey, I. D. (2004), "Electrostatic Hazards in the Process Industries," Process Safety and Environmental Protection, 82(2), pp 132-141. doi:10.1205/095758204322972771

(4) Lang, T. (2015), Filtrationsspezifische Untersuchung der Elektrostatischen Aufladung Niedrig Leitfähiger Hydrauliköle bei der Filtration und Optimierung Eines Filtermediums Hinsichtlich der Vermeidung Elektrostatischer Kontaktaufladung [Filtrationnspecific Investigation of Electrostatic Charge of Low Conductive Hydraulic Oils During Filtration and Optimization of a Filter Medium Regarding the Avoidance of Electrostatic Contact Charge]. Dissertation. Fachbereich Maschinenbau und Verfahrenstechnik, Technische Universität Kaiserslautern.

(5) Sasaki, A. (2000), "Generation Problem of Static Electricity during Oil Filtration," Presented at the International Exposition for Power Transmission and Technical Conference, April 4-6, 100-9.9.

(6) Phair, B., Bensch, L., Duchowski, J., Khazan, M., and Tsalyuk, V. (2005), "Overcoming the Electrostatic Discharge in Hydraulic, Lubricating and Fuel-Filtration Applications by Incorporating Novel Synthetic Filter Media," Tribology Transactions, 48(3), pp 343-351. doi:10.1080/05698190591002195

(7) Leonard, J. T. and Carhart, H. W. (1970), "Effect of Conductivity on Charge Generation in Hydrocarbon Fuels Flowing through Fiber Glass Filters," Journal of Colloid and Interface Science, 32(3), pp 383-394. doi:10.1016/0021-9797(70)90123-2

(8) Huber, P. W. and Sonin, A. A. (1977), "Theory for Electric Charging in Liquid Hydrocarbon Filtration," Journal of Colloid and Interface Science, 61(1), pp 109-125. doi:10.1016/00219797(77)90420-9

(9) Lüttgens, G., Blum, C., Künzig, H., Linberg, K., Lüttgens, S. and Schüler, G. (2002), Kontakt und Studium, Vol. 44, pp 1-259, Expert verlag GmbH: Renningen.

(10) Scheffler, T. N. (2000), Kollisionskühlung in Elektrisch Geladener Granularer Materie [Collision Cooling in Electrical Loaded Granular Materia], Dissertation. Fachbereich PhysikTechnologie, Gerhard-Mercator-Universität Duisburg.

(11) Lowell, J. and Rose-Innes, A. C. (1980), "Contact Electrification," Advances in Physics, 29(6), pp 947-1023. doi:10. 1080/00018738000101466

(12) Helmholtz, H. (1879), "Studien über Electrische Grenzschichten [Studies on Electrical Boundary Layers]," Annalen der Physik und Chemie [Annals of Physics and Chemistry], 243(7), pp 337-382. doi:10.1002/andp.18792430702

(13) Choi, H., Kim, H.-B., Ko, S.-J., Kim, J. Y., and Heeger, A. J. (2015), "An Organic Surface Modifier to Produce a High Work Function Transparent Electrode for High Performance Polymer
Solar Cells," Advanced Materials, 27(5), pp 892-896. doi:10. 1002/adma.201404172

(14) Wang, Z. L., Lin, L., Chen, J., Niu, S., and Zi, Y. (2016), Triboelectrification, Springer International Publishing: Switzerland.

(15) Lee, L.-H. (1991), Fundamentals of Adhesion, Springer US: Boston.

(16) Quéré, D. (2008), "Wetting and Roughness," Annual Review of Materials Research, 38(1), pp 71-99. doi:10.1146/annurev. matsci.38.060407.132434

(17) Staudt, J., Leyer, S., and Duchowski, J. K. (2019), "Detailed Characterization of the Effect of Application of Commercially Available Surface Treatment Agents on Textile Wetting Behavior," Coatings, 9(4), pp 219-229. doi:10.3390/coatings9040219

(18) KRÜSS GmbH. (2006), "Upside Down: Surface Energy Measurement of Textiles by Captive Bubble Method." Available at: https://www.kruss-scientific.com/fileadmin/user_upload/website/literature/kruss-ar251-en.pdf (accessed July 17, 2019).

(19) Cherif, C. (2011), Textile Werkstoffe für den Leichtbau: Techniken-Verfahren-Materialien-Eigenschaften [Textile Materials for Lightweight Construction: Techniques, Processes, Materials, Properties], Springer: Berlin.

(20) Slepickova Kasalkova, N., Slepicka, P., Kolska, Z., and Svorcik, V. (2015), Wettability and Other Surface Properties of Modified Polymers, Mahmood Aliofkhazraei, IntechOpen: London. Available at: https://www.intechopen.com/books/wetting-andwettability/wettability-and-other-surface-properties-of-modifiedpolymers

(21) Volta, A. and Banks, J. (1800), "I. On the Electricity Excited by the Mere Contact of Conducting Substances of Different Kinds," The Philosophical Magazine, 7(28), pp 289-311. doi:10. 1080/14786440008562590

(22) Vilitis, O., Rutkis, M., Busenberg, J., and Merkulov, D. (2016), "Determination of Contact Potential Difference by the Kelvin Probe (Part I) I. Basic Principles of Measurements," Latvian Journal of Physics and Technical Sciences, 53(2), pp 48-57. doi: 10.1515/lpts-2016-0013

(23) Vilitis, O., Rutkis, M., Busenbergs, J., and Merkulovs, D. (2016), "Determination of Contact Potential Difference by the Kelvin Probe (Part II) 2. Measurement System by Involving the Composite Bucking Voltage," Latvian Journal of Physics and Technical Sciences, 53(6), pp 57-66. doi:10.1515/lpts-2016-0045

(24) Rezende, C. A., Gouveia, R. F., da Silva, M. A., and Galembeck, F. (2009), "Detection of Charge Distributions in Insulator Surfaces," Journal of Physics: Condensed Matter, 21(26), pp 263002. doi:10.1088/0953-8984/21/26/263002

(25) Nonnenmacher, M., O'Boyle, M. P., and Wickramasinghe, H. K. (1991), "Kelvin Probe Force Microscopy," Applied Physics Letters, 58(25), pp 2921-2923. doi:10.1063/1.105227

(26) Jacobs, H. O., Knapp, H. F., and Stemmer, A. (1999), "Practical Aspects of Kelvin Probe Force Microscopy," Review of Scientific Instruments, 70(3), pp 1756-1760. doi:10.1063/1.1149664

(27) Kikukawa, A., Hosaka, S., and Imura, R. (1995), "Silicon pn Junction Imaging and Characterizations Using Sensitivity Enhanced Kelvin Probe Force Microscopy," Applied Physics Letters, 66(25), pp 3510-3512. doi:10.1063/1.113780

(28) Weaver, J. M. R. (1991), "High Resolution Atomic Force Microscopy Potentiometry," Journal of Vacuum Science and Technology B: Microelectronics and Nanometer Structures, 9(3), pp 1559-1568. doi:10.1116/1.585423

(29) Sadewasser, S. and Glatzel, T. (2018), Kelvin Probe Force Microscopy: From Single Charge Detection to Device Characterization, SpringerVerlag: Berlin Heidelberg.

(30) Technischer Überwachungsverein [TÜV], Société Générale de Surveillance [SGS]. (2011), "Verifikationsbericht Prüfbaustein \#38208E [Verification Report Test Module \# 38208E]." Technical Expert Certificate.

(31) DEKRA Exam. (2013), "Gutachten: Stellungnahme zu Elektrostatischen Aufladungen von Hydraulik- und Schmierflüssigkeiten: 13EXAM 10846 BVS-BI [Expert Opinion: 
Opinion on Electrostatic Charges from Hydraulic and Lubricating Fluids: 13EXAM 10846 BVS-BI].” Technical Expert Certificate.

(32) ASTM D2624-15. (2015), "Standard Test Methods for Electrical Conductivity of Aviation and Distillate Fuels," ASTM International: West Conshohocken, PA.

(33) ASTM D7042-16e3. (2016), "Standard Test Method for Dynamic Viscosity and Density of Liquids by Stabinger Viscometer (and the Calculation of Kinematic Viscosity)," ASTM International: West Conshohocken, PA.

(34) Morra, M., Della Volpe, C., and Siboni, S. (1999), Polymer Interfaces and Emulsions, Marcel Dekker: New York.

(35) Owens, D. K. and Wendt, R. C. (1969), "Estimation of the Surface Free Energy of Polymers," Journal of Applied Polymer Science, 13(8), pp 1741-1747. doi:10.1002/app.1969.070130815

(36) Good, R. J. (1993), "Contact Angle, Wettability and Adhesion," International Journal of Adhesion and Adhesives, 14(1), pp 3-36.

(37) Suzuki, T., Takahashi, K., Kawasaki, M., and Kagami, T. (2014), "Specific Surface Free Energy of As-Grown and Polished Faces of Synthetic Quartz," Journal of Crystallization Process and Technology, 4(4), pp 177-184. doi:10.4236/jcpt.2014.44022

(38) Wu, S. (1971), "Calculation of Interfacial Tension in Polymer Systems," Journal of Polymer Science Part C: Polymer Symposia, 34(1), pp 19-30. doi:10.1002/polc.5070340105

(39) Jachowicz, J., Wis-Surel, G., and Garcia, M. L. (1985), "Relationship between Triboelectric Charging and Surface Modifications of Human Hair." Journal of the Society of Cosmetic Chemists, 36, pp 189-212.

(40) Ahmed, A. and Aurrecoechea, J. (2007), Specification: Specification for Lubricating Oils for Use in Solar Gas Turbine
Engines. Specification number ES 9-224. Solar Turbines-A Caterpillar Company: San Diego, CA.

(41) Kron, G. (2003), Ladungsträgertransport in Farbstoffsensibilisierten Solarzellen auf Basis von Nanoporösem $\mathrm{TiO}_{2}$ [Carrier Transport in Dye-Sensitized Solar Cells Based on Nanoporous $\mathrm{TiO}_{2}$, Dissertation. Fakultät Informatik, Elektrotechnik und Informationstechnik, Universität Stuttgart: Stuttgart.

(42) Schmitz, A., Duchowski, J. K., and Lang, T. (2014), "Verfahren zur Oberflächenbehan-Dung Eines Filtermediums [Method for the Surface Treatment of a Filter Medium]," German Patent DE 102012020615 A1.

(43) Duchowski, J. K. and Lang, T. (2019), "Method for Adapting a Filter Medium to Predefinable Parameters," European Patent 15708437.7.

(44) Duchowski, J. K. and Lang, T. (2015), "Verfahren zur Anpassung Eines Filtermediums an Vorgebbare Parameter Sowie Vorzugsweise ein Nach Diesem Verfahren Hergestelltes Filtermedium [Procedure for Adaptation of a Filter Medium to Specifiable Parameters as well as Preferably One made by this Process Filter Media]," German Patent DE 102014003 314.7.

(45) EDS-Systems. (2000), "Triboelectric Generation: Getting Charged." Available at: http://esdsystems.descoindustries.com/ Newsletters/v3issue10.html (accessed July 19, 2019).

(46) Galembeck, A., Costa, C. A. R., da Silva, M. C. V. M., Souza, E. F., and Galembeck, F. (2001), "Scanning Electric Potential Microscopy Imaging of Polymers: Electrical Charge Distribution in Di-Electrics," Polymer, 42(11), pp 4845-4851. doi:10.1016/ S0032-3861(00)00921-6

(47) Galembeck, F., Costa, C. A. R., Galembeck, A., and da Silva, M. C. V. M. (2001), "Supramolecular Ionics: Electric Charge Partition within Polymers and Other Non-Conducting Solids," Journal of Colloid and Interface Science, 73(4), pp 495-510. doi: 10.1590/S0001-37652001000400003 